\title{
La prueba agustiniana de la existencia de Dios *
}

\author{
(Intellectus quaerens fidem)
}

\begin{abstract}
"Nonne manifestum est, eum qui alio interrogante sese intus ad Deum movet, ut verum incommutabile intelligat; nisi eundem motum suum memoria teneat, non posse ad intuendum illud verum, nullo extrinsecus admonente revocari? Manifestum est... Habentes in intimo Deum, ubi certum est et incommutabile omne quod amamus".

San Agustín, De Musica VI, 12, 36 y 48).
\end{abstract}

SUmario: I. Estado de la cuestión y opiniones.-II. El horizonte de la "prueba" es el platonismo.-III. La prueba es enteramente racional.-IV. Pero la fe es necesaria, como conditio, sine qua non.

\section{I.-Estado de La cuestión y opiniones.}

El carácter más profundo y definitivo de nuestra época no es el "radicalismo", como suele decirse. Ese radicalismo es ya consecutivo; es una mera consecuencia del "escepticismo". El escepticismo es ta em1nencia gris que desde la sombra y el anónimo nos está gobernando. Es mury probable que dentro de poco tiempo han de buscar los hombres el apoyo de la autoridad incluso para tener confianza en su propia inteligencia. Otra vez las relaciones entre la autoridad y la razón van a preocupar a los intelectuales. Una vez más, por consiguiente, es preciso volver sobre el tema de las demostraciones de la existencia de Dios, para cortar el paso a das simplificaciones abusivas y periodísticas.

Las incesantes discusiones sobre este problema han ido acentuando y definiendo dos cuestiones previas del mayor interés. Por un lado, la

* Este artículo tiene carácter introductorio. En otra ocasión analizaremos concretamente la prueba agustiniana en sus textos. 
religión y la filosofía presentan el problema de una manera esencialmente distinta ${ }^{1}$; por otro lado, la existencia de Dios no puede separarse de su esencia: cuando se pregunta si existe Dios, hay que saber de qué Dios se trata ${ }^{2}$. Ambos aspectos quedan claramente despejados, si nos referimos al modo cómo plantearon el problema Grecia (en nombre de todos los naturalistas) e Israel (en nombre de todos los sobrenaturalistas).

Un epicúreo y un estoico definen a Dios como "lo mejor que existe en el mundo": reúnen una serie de rasgos ideales, suprimen ciertas imperfecciones; luego se preguntan si unos seres, así definidos, existen realmente o no. Tales seres son siempre Baales, esto es, Naturaleza o energía de la naturaleza. Y ya que ese Dios está cósmica o físicamente unido al mundo (principio conjunto), cualquier hombre puede deducir lógicamente la existencia con todo derecho y con certidumbre, ya sea epicúreo, estoico, platónico o aristotélico: basta que sea naturalista y racionalista. La filosofía grecorromana, en virtud de su dialéctica, demuestra pues realmente la existencia de Dios, apoyándose en un principio conjunto que puede denominarse generación, emanación, nexo físico, participación cósmica. La Divinidad va indluúda en el engranaje de las Causas, Motores, Principios, como la cuerda de un reloj va incluída en el movimiento de las ruedas. Poco importa que se diga que el primer motor es "inmóvill": eso significa que ese motor atrae como un imán, pero es un motor físico y atrae físicamente. Del mismo modo, importa poco que se diga que Dios es "trascendental": la trascendencia no puede ser efectiva: la sola ambigüedad de la trascendencia platónica provocó una ola de escepticismo, y una reacción dirigida por Aristóteles y los estoicos: una trascendencia platónica efectiva sería una contradicción in terminis.

Sabemos que, históricamente hablando, muchos filósofos dudaron de la existencia de Dios o la negaron abiertamente. Pero el motivo de talles dudas y negaciones es ajena a la prueba. Un filósofo grecorromano duda de la "esencia" de Dios, de la mitología, de la cosmogonía, de la literatura y de la historia, etc. En consecuencia niega después que existen dioses tales como los que describe la tradición. Del mismo modo, los escépticos dudan de todo y por ende se muestran recelosos frente a cualquiera demostración de la existencia de Dios. Plutanco, pensando en las

1 H. SchwaNZ, Der Gottesgedanke in der Geschichte der Philosophie, Heidelberg 1913, 100-135.

2 Ibid. 
incongruencias de la mitología, dice en nombre de todos los alegoristas: "vomita esos mitos y enjuágate la boca". Y el pontífice Cotta, en el $D e$ Natura Deorum, de Cicerón, declara que los filósofos no le han enseñado nada acerca de Dios, puesto que sus llamadas demostraciones son puramente hipótesis, sueños y falacias. En ambos casos la resistencia proviene de causas ajenas a la demostración misma. En una palabra, los naturalistas tienen un claro "término medio" para construir un silogismo y demostrar de ese modo, científica y filosóficamente, la existencia de Dios.

El presupuesto de esa demostración es la existencia misma, el concepto ide existencia, la cual para el hombre grecorromano no es problema alguno: el mundo es sistencia, insistencia, subsistencia eterna en sí mismo. El tiempo, el movimiento, la generación y la comupción, son concebidos dentro de un eterno retorno ${ }^{3}$. La existencia de Baal es pues un problema consecutivo, dentro del problema general de la existencia del mundo.

Otro problema muy diferente es demostrar la existencia de Jahvé, esto es, de un Dios personal y creador, ser sobrenatural, sin nexo físico o principio conjunto con el. mundo. El ateo israelita puede conceder muy bien que existen uno o muchos Baales, negando que exista Jahvé. Tal debió acontecer en el Destierro de Babilonia, a juzgar por la reacción de Ezequiel y del Deuteroisaías: pero éstos se refugian en los procedimientos "proféticos" usuales, sin recurrir a procedimientos filosóficos contra los ateos. Y no se ve con claridad cómo podrían recurrir a procedimientos filosóficos, puesto que trabajan sobre la base del dogma de la creación. En efecto, ese dogma impone automáticamente la contingencia del mundo. En ese supuesto, Dios no puede existir, como existen el mundo o las cosas del mundo, como una isla en medio del océano, como un primer motor en una serie de motores físicos, o como un relojero que ha fabricado ya muchos relojes conocidos por experiencia. Se trata pues de demostrar la existencia de un Creador y además Creador libre y personal, es decir, se trata de demostrar la creación libre. Sería demasiado cómodo y falaz creer que lo primero es afirmar la existencia de un "dios" y luego ya se discutirá la naturaleza o la esencia de ese "dios", como hacemos en la vida práctica, pues primero nos preguntamos si

3 C. TResmontant, Comment se pose aujourd'hui le problème de l'existence de Dieu, Paris 1966, 33, 50. 
una cosa existe y luego nos preguntamos qué es y cómo es, anteponiendo la existencia y posponiendo la esencia y la naturaleza. Porque en realidad el término "dios" no es un concepto universal que convenga a varios individuos, conocidos por experiencia y el querer suponer una cosa semejante es ya una falacia. Parece pues que dentro de un "profetismo" no cabe una prueba filosófica de la existencia de Jahvé.

Pero de hecho, después del Destierro de Babilonia, la marea helenista contaminó de filosofía a todo el universo civilizado. También en Israel se ensayaron procedimientos vagamente filosóficos para "demostrar", en especial en el ambiente de Alejandría, tanto en los libros canónicos como en los no canónicos. El Libro de la Sabiduría de Salomón, por ejemplo ${ }^{4}$, arguye contra los mismos filósofos paganos y San Pablo recoge esa corriente judía para argüir a su vez contra los fillósofos ${ }^{5}$. Del mismo modo, los judíos alejandrinos arguyen contra la filosofía griega entera y Filón recoge a su vez esa corriente tradicional de los intelectuales de su pueblo.

Dados estos antecedentes, era natural que judíos y cristianos pretendieran "demostrar" la existencia de Dios, dirigiéndose a los paganos que admiten Baales, o dirigiéndose a los ateos. Hallamos esbozos de la demostración en Arístides, Atenágoras, Minucio Félix, San Cipriano, Tertuliano, Lactancio, Gregorio Nacianceno, Hilario, Basilio, Justino y Metodio de Olimpia. Todos tratan de conjugar la Biblia con el estoicismo y platonismo. Sabían que su Dios era diferente de "esos dioses que no hicieron el Cielo y la Tierra" (Jeremías), y que Filón de Alejandría había terminado en una "teología negativa", pero se atenían al significado histórico del término "dios" 6 .

San Agustín es el último gran ensayo de ese tipo. Los horizontes en que se ha de colocar la prueba agustiniana de la existencia de Dios son la Biblia y el De Natura Deorum, de Cicerón. Pero la demostración de Agustín es particularmente interesante, puesto que su autor trae dos novedades importantes: en primer lugar, tiene del platonismo una idea personal; en segundo lugar, se ha empeñado en una refutación radical

4. Sap., c. 13-15.

5 Rom. 1, 20. Cfr. Act. 14, 15 (Discurso de Lystra) y Act. 17, 24-28 (Discurso del Areópago. Cfr. B. GaERTNen, The Areopagus Speech and Natural Revelation, Upsala 1955.

6 Los apologistas repitieron la conducta de los judíos en Alejandría, demostrando que no eran "ateos" y que su doctrina coincidía con lo mejor de la filosofía sin sus defectos. Cfr. J. RATzINGER, Volk und Haus Gottes in Augustins Lehre von der Kirche, München 1954, 6 ss. 
del escepticismo. Estos dos rasgos significan que Agustín rechaza tanto a Xenófanes como al pontífice Cotta, mostrando que sus objecciones son ajenas a este problema, quitándoles así la base de tales objeciones. ¿Podrá entonces trasladar al campo cristiano las pruebas de la filosofía?

$\mathrm{Si}$ nos fijamos un momento en esos dos rasgos mencionados, vemos que Agustín define el platonismo como "reducción del Mundo Inteligible a Dios"; se trata de un error histórico, de una atribución indebida, pero ¿ipodrá Agustín, con ocasión de su enror histórico, construir una prueba filosóficamente válida acerca de la existencia de un Dios cristiano? Del mismo modo, Agustín muestra que precisamente la prueba de la existencia de Dios es la superación del escepticismo y del relativismo. Tiene pues razón Cotta en decir que un escéptico no puedè admitir la existencia de Dios; pero tiene también razón Agustín al decir que quien demuestra la existencia de Dios no puede ser escéptico. Si no existe Dios, no hay otra filosofía que el absurdo ni otra ontología que el nihilismo: una filosofía sin Dios es un castillo en el aire y Agustín pretende realizar lo que Platón hubiese deseado o podido realizar ?

Se trata de una demostración noética, principio y fundamento de cualquiera otra prueba cosmológica, moral o estética. Muchos la miran con recelo, como carente de validez científica, o como si tratase de suplantar las pruebas cosmológicas o morales tradicionales. Otros, sin embargo, sienten hacia ella una fascinación apasionada, ya porque parece resucitada por las actuales corrientes del pensamiento teológico, ya por la variedad de opiniones.

Conocidas son las claras direcciones que la "nueva teología" mantiene en este terreno de la prueba. La reacción contra el pietismo, la teología dialéctica, las doctrinas escatológicas, la oposición al "helenismo" han obligado a los pensadores a referirse directa o indirectamente a San Agustín ${ }^{8}$. El espíritu "existencialista" de la época obliga a todos a no contentarse con "racionalismos" superficiales y a llegar al fondo de los problemas. Pensemos, por ejemplo, en el análisis de la prueba "ontológica", de K. Barth, o en el nuevo horizonte en que pretende colocar las pruebas X. Zubiri ${ }^{9}$. La prueba agustiniana es cada vez más

7 De Vera Religione 3,3 ss, PL. 34, 124 ss.

8 Baste dejar aquí consignados los nombres de Schoonenberg, Brinktrine, Lubac, Blondel, Dondeyne, Mareschal, Epping, Guardini, Sciacca, Weterman, Urs von Balthasar, K. Rahner, Schillebeeckx, para recordar el interés despertado. 9 K. BARTH, La preuve de l'existence de Dieu. Fides quarens intellectum. Neuchatel 1958. Ell primer estudio fue elaborado ya en 1930 ; X. ZuBIRI, Natura. 
interesante, pero se la interpreta como prueba de autoridad, proyección sentimentail, postura vital, experiencia de $\operatorname{Dios}^{10}$.

El P. Cayré, representando a la tradición católica, dedicó un libro entero al estudio de las pruebas agustinianas ${ }^{11}$. Esta interpretación "aristotélica" se empeña en presentar la prueba agustiniana como una "técnica", y así se atiene exclusivamente al De Libero Arbitrio y al De Vera Religione, sin adventir que se trata de la espina dorsal del sistema agustiniano. El P. Cayré se debate en una contradicción inevitable: afirma el valor científico, filosófico y racional de la prueba, incluso exagerando, ya que niega la necesidad de la fe para esta prueba; pero, temiendo peligros de panteismo, intuicionismo, etc., la considera como motivo de consolación y edificación para fines ascéticos y místicos, para pruebas "sobrenaturales": la famosa Homilía 4I, versión popular pero maravillosa de la prueba, es presentada como un sermón ascético y místico ${ }^{12}$. Para evitar peligros imaginarios escoge como base un texto agustiniano, que es clarísimo, pero que con la interpretación aristotélica se vuelve confuso y equívoco también ${ }^{13}$.

Sciacca es sin duda quien mejor ha calado el sentido y la formulación de la prueba agustiniana de la existencia de Dios. Prescindiendo de algunas limitaciones indebidas que introduce, por influencias de Rosmini y por miedo al "cartesianismo" idealista, su libro es la mejor exposición posible de la prueba agustiniana de la existencia de Dios. Sciacca defiende con valentía la validez formal de la prueba, rechaza algunos aires de monopolio que se arrogan todavía ciertos autores tradicionales y nos presenta la prueba, no como una técnica, sino como problema totalitario y fundamental, que pone a prueba al hombre entero y a su razón en concreto. Insiste además en que no se trata de problemas arqueológicos, ya que éste es el problema de la actualidad y aún del porvenir inmediato ${ }^{14}$.

leza, Historia, Dios, Madrid 1944. El estudio "En torno al problema de Dios" fue publicado ya en 1935 .

10 J. A. Mourant, en Philosophical Studies 12 (1963) 92-106. Luego citaremos a algunos católicos que se pronuncian en estos sentidos "modernos".

11 F. CAYRE; Dieu présente dans la Vie de l'Esprit, Paris 1951.

12 Considerabo terram: facta est terra... Haec miror, haec laudo; sed Eum qui fecit haec sitio. Redeo ad meipsum... Quando anima mea contingeret quod super animam meam quaeritur, nisi anima mea super seipsam effunderetur? (Enarrat. 41, 7, PL. 36, 468. Cfr. CAYRÉ, Dieu présent, 39 ss., 41).

13. Nec quisquam est melius rationali anima nisi Deus. Cum igitur intelligit aliquid quod semper eodem modo sese habet, ipsum (Deum) intelligit sine dubio. Haec autem est veritas (Retract. I, 1, 26, PL. 32, 627).

14 IM. F. ScIaccA, L'Exixtence de Dieu, Paris 1951. 
Si Sciacca no ha formado escuela, es indudable que su influencia ha llegado a muchos pensadores, especialmente en Italia. Lo cual ha de ser señalado porque es una ventaja, pero también una desventaja. Una ventaja, porque ha señalado con mano segura la dirección precisa, evitando los peligros de la izquierda y de la derecha a sus continuadores; pero también una desventaja, en cuanto que muchos se sienten de ese modo autorizados para "continuar" a San Agustín, antes de haber precisado y fijado la exégesis histórica y crítica ${ }^{15}$. No negamos que en realidad toda interpretación de San Agustín es en cierto modo "continuación", pero insconsciente: cada generación y cada individuo lee a San Agustín con sus propios ojos. Lo que no se puede hacer es continuarle de propósito, con consciencia de que nos hemos apartado de una interpretación objetiva y literal.

Más peligrosas son, por el espíritu y forma modernos que las informan, las interpretaciones sobrenaturalistas-místicas ${ }^{16}$, existencialistasafectivas ${ }^{17}$, o pietistas experimentales ${ }^{18}$. Es lícito recurrir a la filosofía moderna en muchas de sus tendencias y doctrinas, ya que pueden ser comunes con San Agustín. Pero no es lícito recurrir a tecnicismos anacrónicos intencionadamente, hablando de "procedimientos vitales", opuestos a las "frías pruebas de la razón", sacando a plaza nombres como Riçardo de San Víctor, San Buenaventura, Escoto, Pascal, Rosmini, Blondel y Sciacca ${ }^{19}$. Es lícito asimismo afirmar que en los Padres no se puede separar la filosofía de la teología; pero no es lícito afirmar que las disciplinas que van juntas quedan irremediablemente confundidas ${ }^{20}$. 1963.

15 F. Piemontese, La Veritas agostiniana e l'agostinismo perenne, Milano 16 M. OLtRA, “¿Cómo se reconoce la revelación natural, según San Agustîn"?: Augustinus 10-11 (1958) 281.

17 R. LAzARINI, "C'é una intenzionalitá nella conoscenza, secondo la gnoseología agostiniana?": Augustinus 10-11 (1958) 205-213. Quizá pudiera el amor ser considerado como "intencionalidad". Pero aun en ese caso, nada tendría que ver con la intencionalidad agustiniana fundamental, que es atención-intención, esto es, consciencia, función intelectual.

18 J. I. AlCoRTA, "El conocimiento divino, según San Agustín": Augustinus 10-11 (1058) 310 ss.

19. Sciacca ha declarado expresamente que las razones pascalianas del corazón son para él razones de una inteligencia total y personal. Cfr. ScIACCA, L'Existence... 40. Lo mismo ha hecho Blondel. Cfr. M. Blonder, "L'Unité originale et la pensée permanente de la doctrina philosophique de Saint Agustín": Revue de Métaphysique et de Moral (1930) 424. No es lícito pues recurrir a estos autores en contra de su intención expresa. 24 ss.

20 Cfr. E. STEIN, Endliches und ewiges Sein, Louvain-Freiburg 1950, 12 ss., 
En San Agustín la filosofía y la teología van juntas, pero ninguna es esolava de la otra, ni invade el terreno de la otra.

II.-EL hoRIzonte DE LA "pRUeba” es el pLATONismo.

El sentido genérico de una demostración agustiniana es el platonismo, ya que Agustín no profesó otro sistema filosófico. Aunque leyó a los platónicos con ojos cristianos, también interpretó la Biblia y el $D e$ Natura Deorum, de Cicerón, con mentalidad platónica. Por lo mismo, toda su cosmología y metafísica queda condicionada por la crítica, si bien también la crítica queda condicionada por sus supuestos metafísicos y religiosos. Por consiguiente, el hombre tiene que comenzar por replegarse sobre sí mismo, por entrar en sí mismo. No es un teocentrismo lo que se impone, como suele decirse, sino un antropocentrismo. Todo el sistema tiene que apoyarse en el hombre, en el análisis del hombre, ya por lo que toca al mensaje, ya por lo que toca a la demostración, y tanto si atendemos al aspecto objetivo, como si atendemos al aspecto subjetivo. El foco del interés es la mayéutica cristiana, y cabalmente dirigida a una zona misteriosa del alma humana que llamaremos una "cabeza de puente de Dios" o imagen de Dios ${ }^{21}$.

Demostrar es, pues, mostrar algo que ya estaba ahí, aunque no se veía ${ }^{22}$. Es análisis de un factum, de un conocimiento "natural", que es preciso convertir en conocimiento actual y consciente, lo más claro posible. Al principio de su carrera Agustín se mostró muy vacilante, inclinándose hacia Plotino más bien que hacia Platón, llegando a creer que la demostración requerida y definitiva era experimental, era el "éxtasis transformante" y oscuro de Plotino ${ }^{23}$. La visión facial y beatífica de la verdad que se realiza en este mundo y que al parecer han disfrutado los "sabios" platónicos, es la demostración apodíctica: y esa experiencia definitiva es el fundamento aun para los que no la han experimentado y que tienen que referirse a los que la han disfrutado.

21 Damos ya por supuesta la primera parte, que es el análisis del cogito, en un sentido psicológico y empírico, sobre el terreno que llamamos la "memoria sui".

22 Deum recognoscere, Deum recordari (C. Academ. II, 1, 2, PL. 32, 920).

23. De Immortalit. animae 4, 6, PL. 32, 1024: Potest aliquid esse in animo, quod esse in se animus ipse non sentiat. Es claro que Agustín piensa en el platonismo cristiano, esto es, en la "impresión natural" (Cfr. Epíst. VIII, 2, PL. 33, 68. Para el "éxtasis", véase Solil. I, 6, 12, PL. 32, 875 ss.). 
Es menester apoyarse todavía en la fe, mientras no se alcance la purificación precisa y la experiencia mística personal.

Por fin renunció Agustín a la mística y a las experiencias directas y definitivas, ateniéndose en adelante a un sentido escatológico de la visión beatífica. En este mundo sólo vemos en espejo y enigma y vivimos y caminamos en la fe. El abandono de Plotino es el recurso a Platón, a sus procedimientos racionales, a la mayéutica del Menón y del Fedón : se trata de desenterrar un reouerdo impreso o infuso. Mas como Agustín no puede aceptar ya la preexistencia platónica, la prehistoria, el tópos noetós, y en cambio tiene que construir una teoría de la creación, de la formación y de la iluminación cristianas, la nueva mayéutica de Agustín se llamará cristiana.

No se trata pues de un tema accidental, consecutivo o técnico, sino que se trata de una cuestión de vida o muerte para la filosofía y teología de Agustín: es una cuestión de gabinete, y por eso mismo Agustín extrema en el fondo su rigor. El ateísmo no es para él una postura negativa, una simple negación, duda o resistencia, sino una contienda, un desafío en que las posturas racionales han de ser mantenidas, bajo pena de sentencia por abandono de campo. El ateísmo es una postura positiva, en la que se defiende un relativismo absoluto, una identificación total del ser con el tiempo. A Agustín le parece contradictorio e irracional admitir un absoluto y negar un absoluto al mismo tiempo. Cree pues él que toda la contienda se reduce a demostrar que hay o que no hay un absoluto. Entran pues aquí en juego el hombre y su racionalidad o lógica dialéctica.

Agustín trata de analizar la naturaleza del juicio humano. ¿Qué es un juicio humano? Es una sentencia o fallo, que tiene valor absoluto, puesto que se apoya en una ley absoluta. En todo juicio ha de entrar un "es", un ser, una noción "universal" general; ya en el primer juicio humano "yo soy" se evidencia ese "es".

Entiende pues Agustín que el ateo no juega limpio, ya que todo juicio pone en evidencia un "es": se afirma así y se niega al mismo tiempo la existencia de una zona o mundo absoluto, que Agustín va a llamar Dios. El ateo podría afinmar el "es" de una materia eterna, pero Agustín no concibe que el mundo pueda ser eterno, ya que tiempo y eternidad son para él contradictorios. De ahí que Agustín, excluídos los platónicos, juzga duramente a los filósofos, por no haber aceptado lo que él llama "platonismo", la reducción del mundo inteligible a Dios. 
Dios queda pues implicado en la razón humana, en cuanto que ésta. aparece "iluminada". El problema consiste en mantener la trascendencia estriota de Dios, la sobrenaturalidad de Dios, concondando el platonismo con el dogma de la creación, manteniendo al mismo tiempo el ser de las "criaturas" en cuanto criaturas. La participación de la razón humana en Dios no es entonces una simple herencia-recuerdo, una experiencia prehistórica, como en Platón, o una paradosis, o transmisión, como en Plotino, sino una impresión: Dios, al enviarnos al mundo, imprime, infunde en nuestra naturaleza racional las "categorías" o nociones generales, que vamos a necesitar para organizar la experiencia histórica.

Al principio trató Agustín de utilizar este argumento para demostrar la inmortalidad del alma, aseverando que la razón absoluta es un contenido de la razón empírica o viceversa. Después abandonó ese argumento, transformándolo en prueba de la existencia de Dios. La razón humana se mantiene como término medio de un silogismo latente, en cuanto que la luz de Dios se refleja en ella, a pesar de la trascendencia divina, en virtud de un acto creador. La participación no es más difícil de explicar que la misma creación. Sin embargo, es claro que Agustín quiere "demostrar", pues no se trata de un credere, sino de un intelligere ${ }^{24}$. San Anselmo habla de la fe, aunque ésta quiera ser viva y clara. Agustín quiere saber, aunque tenga que pasar por el puente del creer. Es el caso contrario.

\section{III.-LA PRUEBA ES ENTERAMENTE RACIONAL.}

Tenemos que preguntarnos si la fe es necesaria para la prueba agustiniana. A primera vista, la prueba parece independiente de la fe. Fsto se deduce del mismo concepto agustiniano de fe, al tiempo de esbozar la prueba. La fe se ordena a la inteligencia, es esencialmente racional, en oposición a la viciosa credulidad; la fe es temporal y empírica, y en último término es una exigencia de la razón, un escalón o medio para conseguir una inteligencia superior. Colocada entre dos formas de inteligencia, parece solo un momento de esa inteligencia que le da sentido. No aparece un concepto de gracia preveniente y en cambio reina

24 Solil. I, 5, 11, PL. 32, 875. Ibid. I, 6, 12, coll. 875. De Quant. animae 27, 52, PL. 32, 1065 . 
la persuasión de que la razón y la fe han de coincidir tan exactamente que la religión natural y la sobirenatural son la misma cosa.

¿Por qué, entonces, reclama la inteligencia los servicios de la fe? Porque se ve amenazada mortalmente por el escepticismo. Agustín, como tantos otros, vino a la religión porque ya no creía en la filosofía: en todas las épocas escépticas han buscado los hombres un apoyo en la autoridad. Por lo mismo, esa fe parece una nave, vehículo, venda hemostática, purificación moral, ramaje que nos defiende de la canícula racional, alimento de leche, nodriza. Mantenerla más allá de los límites fijados por la inteligencia, sería tan vergonzoso como seguir navegando después de llegar al puerto, o seguir mamando en la edad adulta ${ }^{25}$. La inteligencia es una vis divina general y la fe tiene que estar a su servicio. Los sabios no tienen necesidad de fe, ya que allcanzan directamente lo que podía indirectamente proporcionarles la fe ${ }^{26}$. Esta fe, dominado Agustín enteramente por los prejuicios filosóficos sobre el "sabio", no es una paralela de la inteligencia, sino un preámbulo de la misma. Es una pieza del aparato mayéutico general, con funciones propias de comadrona y de nodriza. Se refiere siempre al reino temporal, mientras que Agustín busca el Est; Est quaero ${ }^{27}$.

Considerada la inteligencia como vis divina, nos une directamente con Dios y constituye una "revelación natural": posee pues la misma absolutez infalible de la fe, siempre que sea "recta". Ambas pueden inducirnos a error, pero es cuando no son rectas. $Y$ no se diga que Agustín se coloca en una contradicción, al presentar el creer como un absoluto y el entender como condicionado ${ }^{28}$. Cabalmente la fe ayuda a que la inteligencia sea recta, en cuyo caso es absoluta: jamás puede producirse una contradicción entre la fe y la inteligencia. Por lo que atañe a la fe, se refiere al hábito subjetivo (fides qua creditur): hay fe

\footnotetext{
25 ...Alimentum accipere cum quis matre nutritur, utilissimum est; cum jam grandis est, pudendum (De Quant. Animae 33, 76, PL. 32, 1077).

${ }_{26}$ Fac... ita paucorum te esse hominum, ut rationes quibus ad certam cognitionem vis divina perducitur, capere possis (De Util. credendi 10, 24, PL. 42, 81). Interior nescio quae conscientia Deum quarendum Deoque serviendum meliores quosque animos quasi publice privatimque hortatur... (Ibid. 16, 34). Nihil horum est necessarium sapienti; quis negat? (Ibid.).

27 In Ps. 38, 7, PL. 36, 419. La estructura misma del alma humana reclama esa subordinación, puesto que la fe es temporalidad y caso concreto, psicología y empirismo: sólo la inteligencia separa a la fe de la viciosa credulidad y del fideísmo. En cambio la inteligencia guarda en su seno una "cabeza de puente" de Dios y en este sentido es una "potencia eterna". La dialéctica del espíritu es ver el caso concreto a la luz del "principio" o "noción".

28 C. Academ. III, 20, 43, PL. 32, 957.
} 
o no la hay, se cree o no se cree, y la fe puede compararse con la credulidad. Pero si nos referimos al contenido objetivo de la fe (fides quae creditur) la fe se ordena a la visión, y no puede darse postura absoluta hasta que llegue la visión: una fe que no tratara de ver y progresar, no sería búsqueda inteligente de Dios, no sería fe.

En realidad esta fe de la primera época de Agustín comparte sus funciones con el amor: ambos preparan para entender o ver, son preparativos, y tienen que irse convirtiendo en inteligencia superior: son búsqueda, anhelo, deseo de ver, tendencia, secutio, en oposición a la consecutio ${ }^{29}$. Son formas fundamentales de ese impulso interior que nos lleva necesariamente hacia Dios ${ }^{30}$. La búsqueda sería imposible, si no conociésemos a Dios: nadie cree ni ama lo que ignora. Pero sería también imposible, si viésemos a Dios: nadie cree lo que está viendo. De una forma inferior de inteligencia pasamos a la fe y al amor; y de éstos pasamos a una forma superior de inteligencia y conocimiento. En la fe hay que suponer un ánimo de unirse con Dios: si faltase ese propósito, si el alma pretendiera retirarse cuando se acerca Dios, convirtiendo la búsqueda y la espera en un fin en sí mismo, ya no se buscaría a Dios ni se le amaría; se buscaría y amaría la aventura de la persecución. La fe y el amor serían posturas deportivas, puro ejercicio del ante por el arte. Por consiguiente, la antropología platónica de Agustín reclama esa subordinación de la fe.

Esta postura inicial de Agustín fue modificándose paulatinamente. Desde el momento en que renunció a la mística y aceptó la escatología de la visión beatífica, la inteligencia humana perdió categoría en este mundo, pues se hizo asimismo relativa, mientras que la fe se hace ya necesaria para todos los hombres y para toda la vida: buscamos a Dios para encontrarle, péro le encontramos para seguir buscándole y nos debatimos en una mera persecución, sin que en esta vida logremos jamás la consecución. Todavía continuará la fe sometida a la inteligencia, en cuanto que a la hora de la muerte será la fe la que se trocará en inteligencia y no viceversa; pero la visión beatífica no será mera fijación de una inteligencia anterior, sino "galardón" por méritos contraídos por la fe y el amor, aunque también contribuya la inteligencia. Por consiguien-

29 Sequimur diligendo, consequimur vero... intelligibili modo contingentes, ejusque veritate illustrati (De Mor. Eccl. I, 11, 18, PL. 32, 1.319).

30 Ibid. 
te, en el período posterior, tuvo Agustín que reorganizar interiormente todos estos conceptos platónicos.

Al tiempo de la prueba de la existencia de Dios, Agustín se crea dificultades, pero no incurre en contradicción alguna. El platónico no tiene la fe cristiana, pero puede, mediante la iluminación o revelación natural, construir una prueba de la existencia de Dios. Esa prueba, que no necesita de la fe, es tan pobre que Agustín dirá que los platónicos vieron la patria, pero no vieron el camino que conduce a ella ${ }^{31}$. Pero no deja de ser una prueba racional. Se equivoca Agustín acerca de la naturaleza del platonismo, al que atribuye la creación, la formación y el orden cristianos, pero insiste con acierto en que la prueba es racional y no de fe o autoridad, un intelligere, como intus legere, pero no un credere. En este sentido, como veremos luego, la fe queda incluída en la prueba de la existencia de Dios, en una prueba puramente racional. Lid iniciativa viene pues del entendimietno que busca a la fe, no de la fe que solicita la ayuda del entendimiento. Intellectus quarens fidem. La inteligencia misma crea esa disposición subjetiva y absoluta de la fe (fides qua creditur), mientras que la fides quae creditur, el dogma, entra de lleno en el campo de la inteligencia y no puede detenerse ya en un progreso incesante. No es pues una argumentación o demostración redundante para el público, para los insensatos, herejes, corrompidos y ateos: es la justificación necesaria de la misma fe y de la postura religiosa del sujeto Agustín. Si descubrimos colorido polémico y apologético, eso se debe al método, al diálogo, pero no al carácter intrínseco de la prueba.

Tan convencido está Agustín de la pura y estricta racionalidad de su prueba, que se la atribuye a los platónicos, apoyándose en el testimonio de la Epístola a los Romanos: Deus illis maniffestavit, manifestum est in illis ${ }^{32}$. Es más, podemos decir sencillamente que esta prueba es lo que Agustín llama "platonismo", puesto que estima erróneamente que el patonismo consiste en la reducción del tópos noetós a un Dios personal y creador. La prueba se dirige pues a todos los hombres, incluídos los escépticos. El valor de la fónmula crede ut intelligas, aparece a la luz de dos puntos de referencia, o criterios de apreciación: primero, va precedida por otra fórmula antagónica, intellige ut credas verbum memum: ésta da sentido a la primera y no viceversa, como creen tantos autores; segundo, la partícula de finalidad, ut, expresa la esencia misma

31 Sed non noverunt viam (Confess. V, 3, 5, PL. 32, 708).

32 Rom. 1, 19. 
y el sentido de la fórmula, que es relación esencial de la fe a la inteligencia. Por la primera referencia, la fe se define como fe, en oposición a la "viciosa credulidad"; por la segunda referencia, la fe se define como fe en oposición a la fiducia o fe del carbonero, propia del pecus Dei, que se apoya en la fe de los otros, de los espirituales. La fe es un medio, la inteligencia un fin. La fe es microscopio o telescopio, la inteligencia is ojo. El entendimiento reclama la fe como un señor que solicita un vehículo. El mundo de San Agustín y el de Anselmo son opuestos. Hay que aceptar pues las consecuencias: por un lado, imagen natural de Dios, teología natural, analogía del ente y de la fe, síntesis de filosofía y' teología, síntesis de platonismo y cristianismo; por otro lado, penosa búsqueda de Dios, procedimientos mayéuticos, pruebas de la existencia de Dios, renuncia a las experiencias directas de Dios, problematización de la mística, ganar el pan ideal con el sudor de la frente, con el estudio, con la meditación, con tenues evidencias fragmentarias y ambiguas.

La razón humana, dirá luego Agustín, está enferma, apegada a lo sensible; por eso tiene necesidad de la fe. Pero una cosa son los ojos y otra los colirios medicinales. Sustituir la inteligencia por la fe es tan improcedente como sustituir un miembro por una medicina.

IV.-Pero la fe es necesaria, como "conditio, sine qua non".

Agustín evolucionó acentuando más y más la necesidad de la fe y reforzando la prueba racional con el apoyo de la fe, mientras comenzaba ya a desconfiar de los platónicos y acentuaba el carácter de "creación", propio de este mundo. De ese modo las pruebas pienden categoría y se envuelven en el misterio mismo de la creación. La supresión del naturalismo griego significa pura y sencillamente la supresión del helenismo como sistema; se le utiliza ya para algo que no es helénico. Agustín queda pues en una postura muy difícil.

El mundo aparece en virtud de una palabra libre, esto es, de un pensamiento. Por ende, demostrar la contingencia del mundo es lo mismo que demostrar la creación. Estamos ante un misterio, puesto que ya no hay término medio entre el mundo y Dios y la Naturaleza no es sino un atributo divino: al suprimirse la "necesidad" queda suprimida la dialéctica, que se apoya en esa necesidad. Por eso las pruebas tradicionales de la existencia de Dios se quedan en un Dios Motor, 
causa o principio: para demostrar la trascendencia y personalidad de Dios tendrían que suponer que el acto creador es comprensible y explicable en sí mismo para la inteligencia humana. Esto, sin embargo, es más que discutible. ¿De qué premisas podríamos deducir el acto creador, si todo depende de una voluntad libre? Parece que sólo podemos conocer ese acto divino por revelación sobrenatural: sin fe no habría demostración.

Por otra parte, al relegar Agustín la visión beatífica a la vida futura y escatológica, el conocimiento intelectual de Dios se convierte en un mero "Ideal" inasequible: descubrimos analogías, vemos en espejo y enigma, como el mismo Agustín repetirá tantas veces ${ }^{33}$. Es verdad que, al no ofrecernos una teoría especial del lumen gloriae, parece suponer que el conocimiento de este mundo se transforma sin más en el conocimiento beatífico. Pero desde el momento en que la visión beatífica no es una mera continuación del conocimiento terreno, sino un "galardón" por los méritos de la vida entera, como Agustín repite, no es sola la fe la que se transforma en visión, sino que también la inteligencia terrena se transforma.

Es verdad que Agustín insistirá en hablarnos siempre de la razón. Pero su razón no es nuestra razón autónoma, emancipada de la fe. Desde el principio de su conversión justificó la necesidad de la fe para la vida racional, no ya para adquirir un conocimiento superior, sino para liberarse del escepticismo filosófico, al que había llegado filosofando. La historia de sus errores pasados le demuestra que la razón humana está enferma y apegada a lo sensible, y necesita apoyos para proceder con firmeza. La salvación de los platónicos o "sabios" se convierte en un recurso: ven la patria, pero no ven el camino: pero para que vean esa misma patria, Agustín les atribuye una interpretación errónea. Finalmente, poco tiempo después, niega ya la salvación a todos los que no tengan fe, incluídos los sabios. Esto demuestra que se trataba de otra cosa: lo que quería hacer ver Agustín, contra Porfirio, es que existe un camino universal de salvación para todos los hombres, y no sólo para los "sabios": ese camino es la religión cristiana: No tiene ya importancia si en virtud de una interpretación errónea, atribuye a los platónicos la religión cristiana, por lo menos en la parte que le interesa: creación, formación, orden del universo, reducción del Bien, de la Ver- 
dad, de la Belleza y del Ser al Dios personal y creador de los cristianos. Se trata de una razón cristiana.

Por eso la fórmula crede ut intelligas no puede tomarse en un sentido absoluto y abstracto, sino teniendo en cuenta el sistema de Agustín. Todo aquel que aspire a entender tiene que aceptar previamente la fe. De ese modo afirma que desde el principio él aceptaba la fe de un moido absoluto y la filosofía platónica tan sólo en cuanto no contradijese a la fe, esto es, en cuanto ayudase a entender la fe. No nos apresuremos, sin embargo, a concluir que en ese caso estamos ya en San Anselmo; aún no hemos definido de qué necesidad de la fe se trata.

Al insensato, y en esa categoría entran todos los hombres que no tienen fe, hay que invitarle primero a creer. De otro modo, no sabrá de qué Dios se trata y se contentará con un Baal o Motor del Universo. Eso no significa que la prueba sea teológica, pues la necesidad de la fe es experimental: cada día tenemos ante nosotros a los infieles, que no entienden lo que a nosotros nos parece tan claro. Tal es pues el sentido del nisi credideritis, non intelligetis ${ }^{34}$. Los "pocos sabios" que según Agustín, al principio de su carrera se salvan, se salvan gracias a que Agustín les atribuye el Cristianismo, aunque él lo llama platonismo ${ }^{35}$.

La prueba es filosófica, pero una vez que interviene la fe. Reduciendo esa necesidad de la fe al mínimum, hablaríamos de una conditio sine qua non. Una vez admitida la creación, gracias a la fe, es ya posible organizar la prueba, atribuyéndola a un Dios personal y creador. Advirtamos, sin embargo, que la creación misma es un misterio, y esto es lo que para muchos modernos hace imposible la prueba racional y pone a Agustín en entredicho. Es preciso añadir, sin embargo, que quizá Agustín no vio más misterioso este problema, que otros muchos que presenta la filosofía. Objetivamente, se supone la fe. Subjetivamente, la prueba es racional y la fe es un mero presupuesto. Agustín sabía que durante su escepticismo no perdió la fe en Dios ${ }^{36}$. Se puede ser escéptico y creer en Dios como el Pontífice Cotta. Después de creer, la fe misma nos obliga a seguir adelante hasta saber.

34 Is. 7, 9, según los LXX.

35 Neque quisquam inveniendo Deo fit idoneus, nisi antea crediderit quod est postea cogniturus (De lib. arb. II, 2, 6, PL. 32, 1.234).

36 Idipsum maxime credendum erat, quoniam nulla pugnacitas calumniosa per tan multa quae legeram inter se confligentium philosophorum, extorquere mihi potuit ut aliquando non crederem, Te esse quidquid esses, quod ego nescirem (Confess. VI, 5, 7, PL. 32, 723). 
Pero los autores modernos no abandonan su preocupación, ya que es preciso tener también en cuenta otros presupuestos agustinianos: éstos, sin embargo, más bien favorecen el carácter racional de la prueba:

a) La llamada independencia de la razón no se da ni de hecho ni de derecho. Toda razón se apoya en mitos, prejuicios, leyendas, ambientes, idolatrías, suposiciones, educación, cultura y circunstancias muy discutibles. En cuanto al derecho, los primeros principios y nociones en que se apoya toda construcción racional, son racionalmente indemostrables. Partimos siempre de un campo irracional e inconsciente. Agustín fue uno de los escasos hombres antiguos que vio que el hombre es ante todo y sobre todo "memoria", esto es, relación constitutiva e inconsciente con un pasado. Por eso, fue el primero que propuso, no sálo esa prueba de la existencia de Dios con valor filosófico y religioso, sino también una prueba de la existencia del yo, que es también un problema, aunque to nieguen irracionalmente los existencialistas ${ }^{37}$.

Es dlaro que Agustín tiene razón. Desde los tiempos de Cristo, toda razón humana está de hecho más o menos iluminada por la fe. Aunque en el helenismo la razón humana se hubiese apoyado en sí misma, y no en los mitos y prejuicios, como es el caso, después de Cristo es imposible regresar a la inocencia pagana. La luz de Cristo ha llegado a todos los escondrijos de la tierra, directa o indirectamente, y una razón humana independiente es una mera abstracción para fines metodológicos, pero inexistentes. Si pues, a pesar de eso, hablamos de "escuelas filosóficas (todas las cuales presuponen una discusión con los cristianos), seguramente podremos hablar de una "escuela de Cristo", no ya sólo en el terreno teológico y religioso, sino también en la exposición racional de unas doctrinas cristianas con métodos filosóficos.

$\mathrm{La}$ fe es, pues, mero punto de partida, metódicamente comparable a cualquiera otro presupuesto indemostrable. En cambio, la prueba en cuanto tal, es dialécticamente racional y fillosófica. A cualquiera filósofo le es lícito preguntarse si existe Dios y contestar en formas racionales, aunque haya oído exponer la fe cristiana. Otra cosa será luego examinai si la prueba misma es racional y válida. Ahora sólo tratamos de la legitimidad de construirla, dado el presupuesto de la fe.

Por todo lo dicho, hay que concluir que San Agustín y San Anselmo son dos polos opuestos. San Anselmo, como todos los pensadores

37 Ego autem et a me discesseram, nec me inveniebam; quanto minus Te? (Confess. V, 2, 2, PL. 32, 707). 
medievales, vive enteramente sumergido en un mundo de gran fe, y se apoya ien la autoridad teológica o filosófica. No se enfrenta con un escepticismo o un ateísmo radicales y vivos que le hagan frente. Agustín vive en un mundo escéptico, como el nuestro, en un mundo ávido de pruebas y claridades, en un mundo muchas veces engañado, y por lo mismo acuchillado y avisado, que reaccionaba con dessconfianza y recelo, cuando oía hablar de fe o de entendimiento. ¿Cómo comparar al angelical San Anselmo, educado en un convento desde su infancia, con un Agustín turbulento y derrotado, que al respirar las áuras de la libertad, mira todavía con terror a su pasado? Este es el abismo que separa a Agustín de la Edad Media.

La existencia de Dios es un dogma para la fe, porque implica el problema de la esencia de Dios. Esa creencia, no demostrada, sirve de orientación a la razón, como otros postulados semejantes. Una vez informada la filosofía sobre la esencia del Dios cristiano, para poder plantear bien el problema de la existencia de ese Dios, la demostración filosófica es enteramente racional. Es verdad que la existencia de Dios no queda condicionada por la prueba. Pero se trata aquí de un principio: la existencia de las cosas no depende de que nosatros acentemos a demostrar su existencia. Por otra parte, la demostración filasófica no es enteramente necesaria para quien tiene fe y ha recibido la divina revelación. Gracias a la divina revelación, el filósofo tiene seguridad en sí mismo y ordena la rectitud de su razonamiento, en la convicción de que jamás podrá la razón humana demostrar que Dios no existe. Por ende, lo único que podemos exigir a un filósofo que pretende demostrar racionalmente la existencia de Dios es, no que demuestre el punto de partida (cosa imposible para todos) sino que su prueba racional sea "recta", auténtica, lógica. Pues bien, es evidente que San Agustín pretendió demostrar racionalmente la existencia de Dios.

De nada sirve recurrir a consideraciones piadosas o teológicas, para concluir que San Agustín tenía que atender al aspecto teológico más bien que el filosófico. Dice con razón K. Barth, al hablar de la existencia de Dios en San Anselmo, que la teología es plegaria, y que por esa razón la demostración ha de ser teológica. Eso es cierto. Pero en el sistema agustiniano también la filosofía es plegaria, y por cierto la mejor y más íntima. El conocimiento se explica por una iluminación divina, por una subjunctio natural, que significa un contacto permanente y natural del entendimiento humano con Dios. Creer no es ver, ya que la autoridad es 
siempre externa. En cambio, ver es percibir dentro del alma, a la luz del mismo Dios. Una prueba de la existencia de Dios aunque se llame cosmológica, es siempre noética, pues es un intus legere. Suprimid el principio de causalidad, que no es ningún objeto cosmológico, y veréis cómo construis una prueba cosmológica. Lo importante para Agustín es pues siempre, el análisis del entendimiento humano. Si este entendimiento humano no vale para demostrar la existencia de Dios, podemos renunciar a toda demostración racional.

En cuanto al concepto de existencia, deberemos también tomar algunas precauciones, si queremos entender lealmente el pensamiento de San Agustín. Su análisis del entendimiento humano va a poner en evidencia la existencia de las "nociones", que son como las categorías fundamentales del entendimiento. Por un lado, yo me veo obligado a afirmar racionalmente la existencia de las nociones fuera de mi pensamiento, ya que las encuentro en mi pensamiento; yo no podría pensar en la justicia, en la belleza, verdad, realidad de los objetos, si estas realidades no existieran fuera de mí: son causas y no efecto de mi pensamiento. No es posible un "acto estético" para quien carezca de la noción de belleza; pero la belleza no la crea quien la ve: no es posible un acto "moral" para quien carezca del sentido de moralidad; pero la moralidad no la crea el sujeto, y así sucesivamente. Sin los hábitos preparatorios e infusos correspondientes, que cubren diferentes campos de la realidad y de la experiencia humana, son imposibles los actos, pues todo acto sobre un objeto supone un caso concreto y una noción universal. Mas, por otro lado, hay una desproporción radical entre la razón empírica y la razón absoluta, inmutable y eterna, que descubrimos en las nociones. Las poseemos pues, no por derecho propio (natura), sino por participación (dono creationis, impressione). Por eso, hemos hablado de la "cabeza de puente" de Dios.

Esto quiere decir que nos abstengamos de considerar la existencia de Dios o de la "noción" a la manera en que existen los demás objetos que hay en el mundo, y que son objetos, no condiciones previas del pensamiento, luz del pensamiento. Atribuímos racionalmente a las nociones el praesto esse, la presencia, porque "en ellas nos movemos, vivimos y somos". Su existencia es un postulado de nuestro pensamiento racional : la demostración trata sólo de hacernos reflexionar, de hacernos ver los "hechos", tales como son. Un hombre no podría hablar racionalmente de existencia, si no supiera desde antes de nacer qué es existir; 
la noción impresa ide existencia supone ya que la existencia es un hecho: el hombre tiene que reflexionar sobre la luz que él descubre en sí mismo y en el mundo. Se requiere la fe para no engañarnos acerca de la naturaleza o esencia de Dios, para saber de qué Dios se trata. Pero eso supuesto, es preciso explicar lógicamente la existencia de la existencia y de la luz que hace existir. Los "objetos" que existen tienen una existencia gratuita: no puede ser deducida de nada, ya que no hay necesidad alguna ni dialéctica que reclame su existencia. Pero la existencia de Dios, como Principio y Fundamento trascendental de la existencia, implica una necesidad absoluta.

Por eso, para demostrar la existencia de un objeto, no basta demostrar su necesidad, sino que tengo que "comprobar" esa existencia: demostrar es comprobar (ver, oír, tocar, experimentar, recibir la información, inducir): en cambio, la necesidad de la existencia de Dios nos dispensa de experimentar y nos permite contentarnos con una auténtica "demostración" racional. Por lo mismo, no se trata de la necesidad dialéctica o lógica del naturalismo, que inscribe a Dios entre los "objetos" del mundo, como Primer Objeto, Primer Motor, Primera Causa, dentro de un engranaje físico o mundano; se trata de la necesidad dialéctica y lógica de la verdad, belleza, realidad, existencia, Basta demostrar que hay existencia para concluir que existe la Razón de la existencia.

P. Lope Cilleruelo, O. S. A. 